\section{The impact of fluoride application training: survey of trained dental nurses from King's College Hospital NHS Trust}

\author{
E. Carter, ${ }^{1}$ M. Parker ${ }^{2}$ and J. E. Gallagher ${ }^{3}$
}

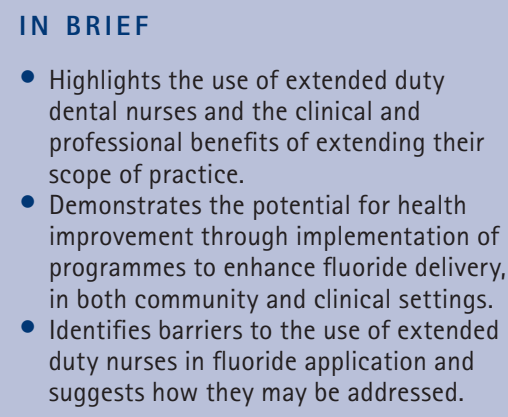

\begin{abstract}
Objectives To explore the perceived benefits of a fluoride varnish training scheme, subsequent use of extended skills and any barriers that exist, in order to inform future training and practice. Method Questionnaire survey of the first four cohorts of fluoride varnish training at one London dental hospital. Results Thirty-six (62\%) nurses responded to the survey, $89 \%$ of whom were using fluoride varnishing. 'Personal development', 'NHS initiatives' and 'having a supportive principal' were key drivers for course attendance. Over 2,500 fluoride application treatments were carried out (range =0-630) with six nurses providing $71 \%$ of the treatments. Twenty nurses (56\%) worked in the salaried primary dental care service and provided $69 \%$ of treatments, the remaining 31\% of treatments were provided by the $44 \%(n=16)$ of nurses in general dental practice. Barriers were 'systems-related' and 'professional', including lack of community programmes, consultant oversight, referrals, materials and concerns regarding insurance and consent. The majority felt that the course contributed to their professional career (97\%), and expressed their confidence in conducting fluoride application (80\%). Conclusion The findings highlight the potential for using extended roles to deliver evidence-based prevention and variation in their use; however, there is some evidence that organisational and professional barriers exist.
\end{abstract}

\section{BACKGROUND}

Fluoride varnish has been shown to reduce dental caries when used as an addition to fluoride toothpaste. ${ }^{1}$ Evidence based guidelines in England recommend the application of fluoride varnish between two and four times annually in all children over three years old and twice annually in adults at risk of developing caries. ${ }^{2}$ Fluoride application is a simple but important procedure that can be delegated to dental care professionals. Following registration with the General Dental Council (GDC) there has been approval for dental nurses to have extended roles including

${ }_{1 *}$ Former Senior House Officer in Oral Health Services Research and Dental Public Health, King's College London Dental Institute at Guy's King's College and St Thomas' Hospitals, ${ }^{2}$ Dental Nurse Manager Training, King's College Hospital NHS Foundation Trust, ${ }^{3}$ Reader in Oral Health Services Research/Hon Consultant in Dental Public Health, Oral Health Services Research and Dental Public Health, King's College London Dental Institute at Guy's King's College and St Thomas' Hospitals, Denmark Hill Campus,

Bessemer Road, London, SE5 9RS

*Correspondence to: Dr Emily Carter

Email: emily.carter1@nhs.net

OnIne article number E15

Refereed Paper - accepted 12 April 2012

DOI: $10.1038 /$ sj.bdj.2012.417

${ }^{\text {QB }}$ ritish Dental Journal 2012; 212: E15 the application of fluoride varnish. This must be as part of a programme which is overseen by a consultant or specialist in Dental Public Health (DPH), as laid down in the GDC scope of practice. ${ }^{3,4}$

In response to the expanding role for dental nurses, King's College Hospital $(\mathrm{KCH})$ Dental Nurses Education and Training Centre (DNETC) began running a certificate in fluoride application in 2009. The course aims to give dental nurses the practical skills and theoretical knowledge required to competently apply fluoride varnish to adults and children on the prescription of a dentist or as part of a community project. Four cohorts of dental nurses had completed their training at the time of the study; two of these groups were comprised of a mixture of community and general practice nurses and had a blended learning course using online modules and two days of face to face teaching. A further two groups were dental nurses from community dental practices, who had a four-day intensive course. All students had to submit four written assignments and a portfolio of supervised experience to demonstrate their clinical competence within the workplace. Successful completion of the course was judged by the course organizer and an independent moderator. Following completion of the course, nurses are able to carry out fluoride application in their workplace and as part of community programmes. Given the significance of this change in professional practice it was considered important to follow-up these nurses and explore their experiences in using fluoride varnishing skills and wider preventive practices.

\section{METHOD}

The views and experiences of all cohorts of dental nurses who attended the fluoride application course since 2009, with at least two months post-qualification experience, were sought by means of an online questionnaire. This study was approved as a service evaluation by King's College Hospital Ethics Committee. The survey, designed to take less than ten minutes to complete, was informed by Dillman's approach to surveys ${ }^{5}$ and constructed using the 'Survey Monkey' website (http://www. surveymonkey.com/) which enables accessible online completion and instant access for analysis. The questionnaire instrument was designed to meet the objectives of the 
evaluation and piloted with nurses in the centre who were not part of the study sample. The e-mail addresses of the nurses who took part in the course were used to send out the online survey. To encourage participation, dental nurses received three e-mails over a period of three weeks. ${ }^{5} \mathrm{~A}$ further e-mail was sent to all participants to inform them that the survey was closing and provide them with a final chance to respond. For any nurses without e-mail addresses or where their e-mail address was found to be invalid, postal addresses were obtained from the GDC website and a paper copy of the questionnaire was sent together with the internet address, so they had the option to complete an online version. A freepost envelope was included to encourage responses. Fifty-eight nurses were identified as having completed the course, 56 e-mail addresses were available of which 51 were valid. Seven were sent paper questionnaires. Data were transferred to excel for descriptive analysis. Responses to open questions were analysed conceptually for key themes.

\section{RESULTS}

\section{Respondents}

Thirty-six nurses completed the questionnaire giving a response rate of $62 \%$. of the 33 nurses who provided information on their age $66 \%(n=22)$ were over 30 years old and the remaining 34\% ( $\mathrm{n}=11)$ were aged 20-29 years. Eighty percent were British born $(\mathrm{n}=28)$; the remaining seven respondents were born in a variety of other countries. Thirty-five respondents provided details of their ethnic origin, with $80 \%$ ( $n=28$ ) of nurses describing themselves as White/White British. The remainder were Asian/Asian British or Black/Black British.

\section{Qualifications}

The majority of the dental nurses (89\%, $\mathrm{n}=32$ ) reported having a Certificate in Dental Nursing or a Dental Surgery Assistant Certificate, with seven of these nurses (19\%) also having GDC registration based on experience. Eight percent of the nurses $(n=3)$ held GDC registration based on experience only. One nurse did not specify their status. Nineteen nurses (53\%) had a Certificate in Oral Health Education. Five nurses had other qualifications (14\%) in other areas of dental care. Almost half $(44 \%, n=16)$ of the nurses

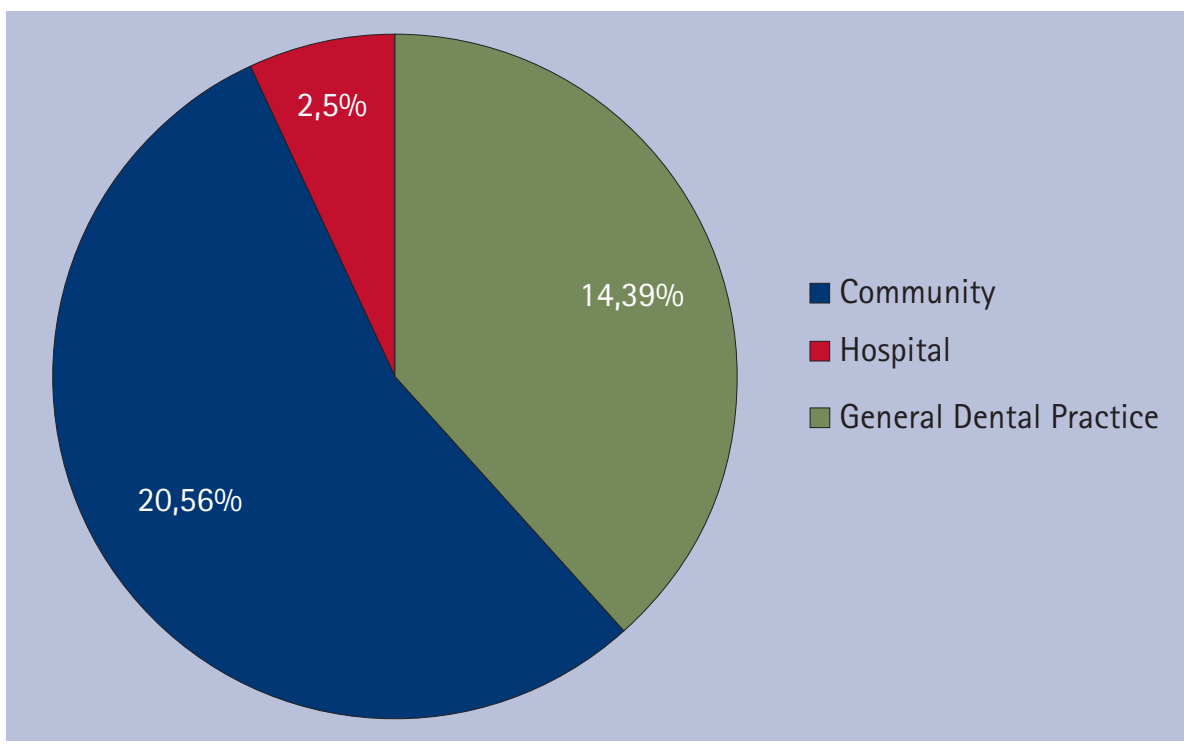

Fig. 1 Respondents main place of work $(n=36)$

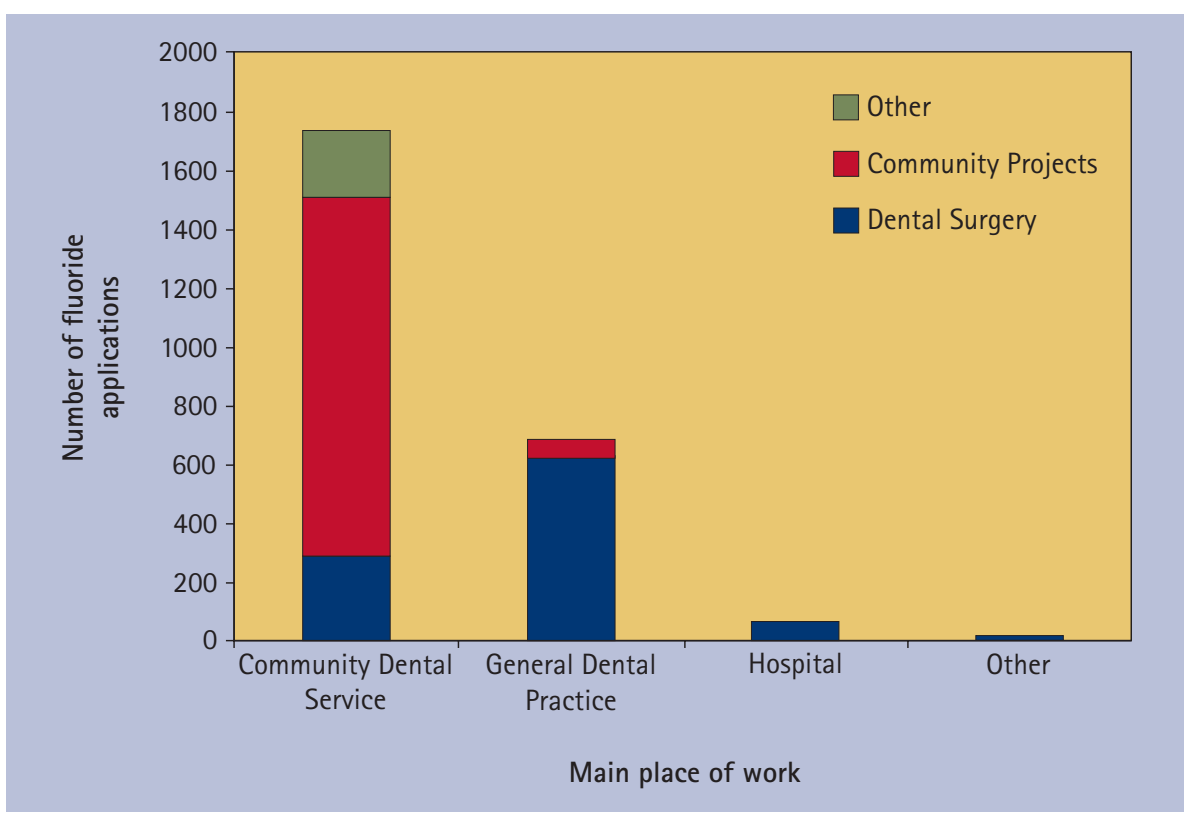

Fig. 2 Number of fluoride application treatments carried out by respondents in different clinical environments grouped by main place of work $(n=2,513)$

reported other nurses with the same qualification working in their practice.

\section{Work environment}

Figure 1 shows the main place of work of the dental nurses with the majority (56\%, $\mathrm{n}=20$ ) in salaried primary dental care.

Twenty-six nurses (74\%) reported working in an environment where almost all treatment was carried out on the NHS. Only two $(6 \%)$ nurses worked in a completely private setting. Over half of the respondents $(56 \%, n=20)$ reported working full time.

\section{Motivation}

The nurses were asked why they attended the course and could select one or more options. Sixty-four percent $(n=23)$ of respondents stated that they attended the course because of personal interest, three of whom were also encouraged by the practice principal and four of whom were part of an NHS initiative. Nine nurses in total (25\%) attended as part of a PCT initiative and a further eight $(22 \%)$ on the instruction of their practice principal.

\section{Use of fluoride varnishing skills}

In total 2,513 patients were reported as having been treated with fluoride varnish by respondents since course completion. In community projects the average number of patients treated with varnish per nurse was 


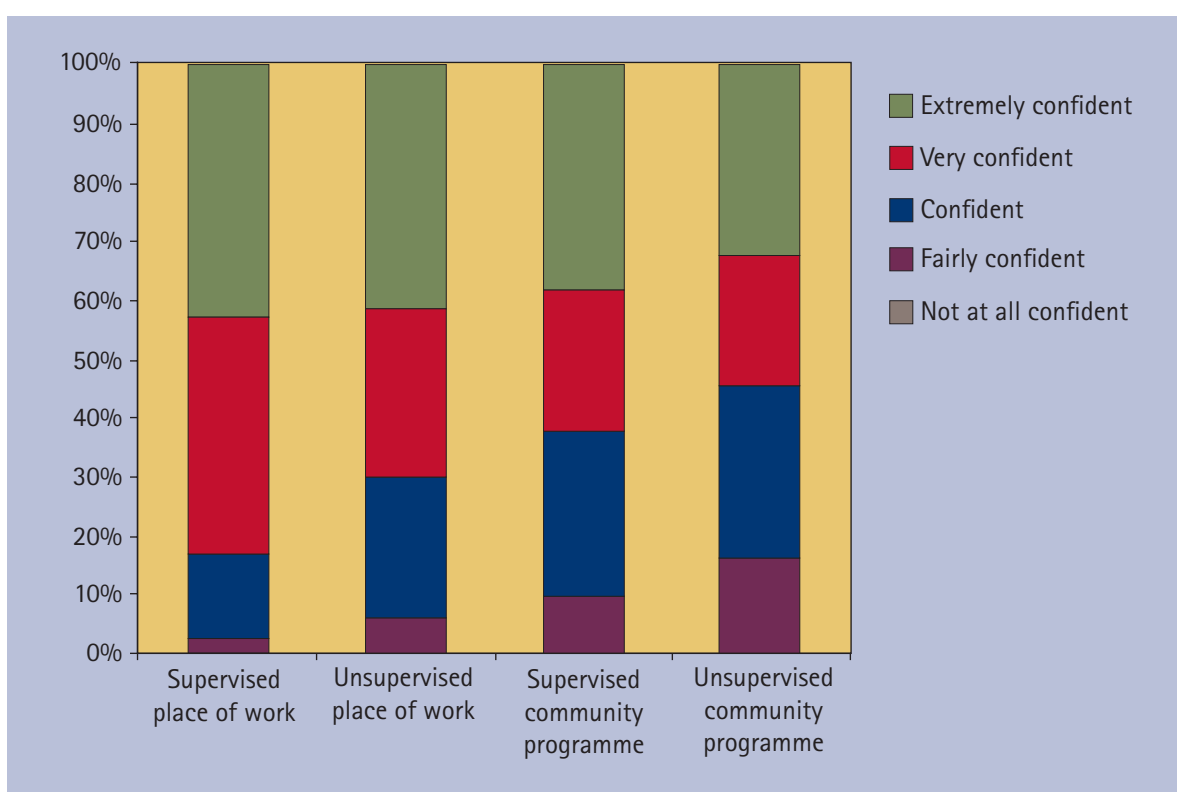

Fig. 3 Confidence of dental nurses when applying fluoride in a variety of clinical situations $(n=36)$

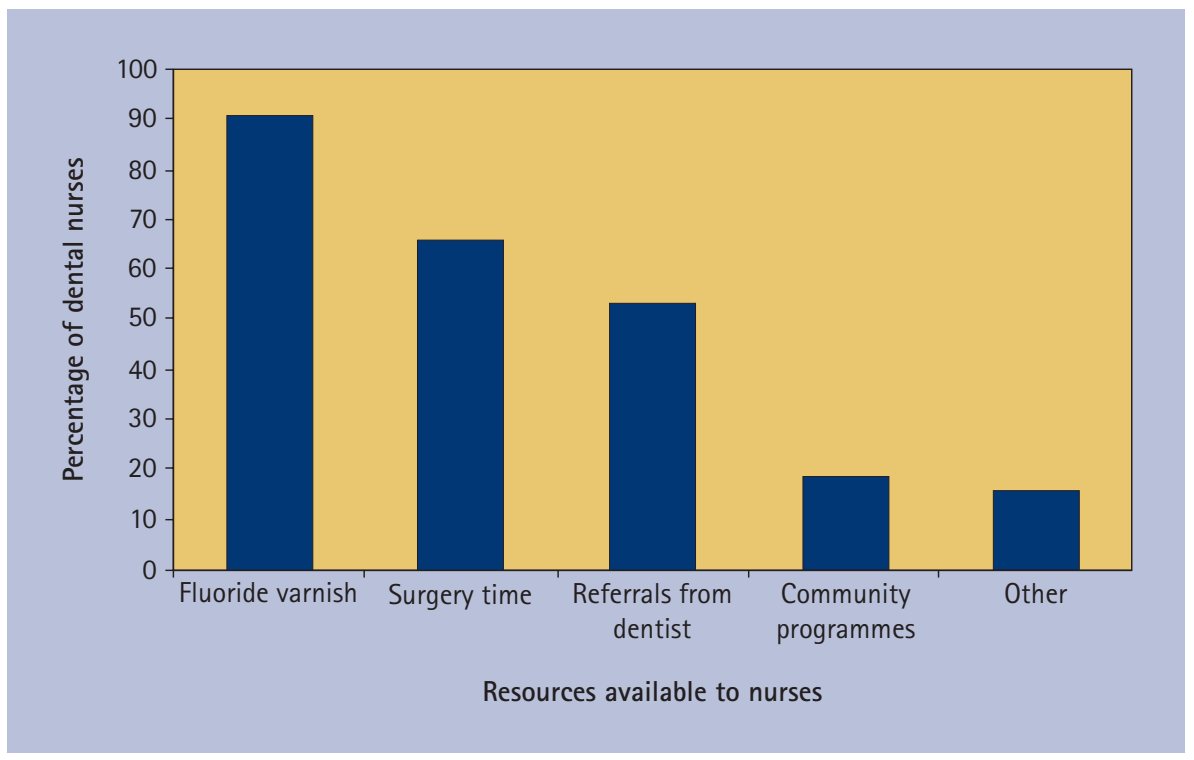

Fig. 4 Resources available to nurses to enable fluoride varnish application $(n=32)$

104 , compared to 40 in the dental surgery and 59 in other clinical situations. Half of all fluoride applications were carried out as part of a community project and $41 \%$ in the dental surgery setting. Nurses whose main place of work was in salaried primary dental care services carried out the most fluoride varnishing (69\%) as illustrated in Figure 2.

The number of months since obtaining the qualification ranged from 2 to 24 . There was no clear association between the number of months since qualification and the number of fluoride applications conducted. Since qualification, six nurses (17\% of respondents) reported carrying out 100 or more fluoride applications each, totalling an estimated 1,780 applications between them. This accounts for 71\% of the total treatment provided, with one nurse in the salaried primary dental care service accounting for an estimated 630 applications in just six months. Another nurse in general dental practice carried out 300 fluoride application treatments over ten months and stated that she had completed multiple other courses as outlined below. Four nurses reported not using their skill at all; of these two worked in the salaried primary dental care service, one in general dental practice and one in hospital; however, two of these nurses had only held their qualification for two months at the time of survey.

\section{Confidence in using skills gained}

Over $80 \%$ expressed confidence in providing fluoride varnishing in all settings (Fig. 3), particularly in their place of work.

\section{Resources available}

Twenty-nine nurses (91\%) reported having fluoride varnish available to use (Fig. 4).

\section{Barriers to use of fluoride application skills}

Sixty-three percent $(n=22)$ of nurses reported no barriers were preventing them from using their skills, with one nurse abstaining. When reported, barriers largely related to the system and nurses' professional role within the team. These included 'lack of community schemes' due to there being no dental public health consultant or 'loss of interest' by the clinical lead. Other issues included: 'lack of delegated referrals from dentists', 'difficulty in being released from core nursing duties', 'problems with insurance' and 'obtaining patient consent'. The challenge of establishing how to use the new skill was illustrated by participants as demonstrated by the following quotations:

- 'As this is a very new process for the whole dental team, it can be difficult to know how to take this forward in a practical and productive [way].

We are working on new methods of fluoride delivery at the moment but it would be good to gain knowledge from other areas as to how they are tackling this' (participant 20, salaried primary dental care)

- '[There is] no set structure of guidance to me or the dentist I work with about how to use my extra skill' (participant 30 , general dental practice).

\section{Impact on career}

Ninety-seven percent of respondents ( $n=35$ ) stated that they thought that gaining the certificate in fluoride application had a positive impact on their career. Since completing the course 29\% of nurses reported taking part in other courses including Oral Health Education, Safeguarding, Impression Taking, Special Care Nursing, Sedation Nursing, Special Needs Nursing, Cross Infection Control and Information Technology. One nurse (respondent 8, general dental practice) reported completing courses in suture 
removal, impression taking and smoking cessation and now runs her own appointment book with referrals from dentists allowing her to carry out a large number of fluoride application treatments as outlined above. Ten nurses also expressed interest in further training and suggested training in re-cementing temporary crowns and help with applying fluoride to children with learning difficulties, along with already existing courses such as radiology, impression taking and suture removal.

There was evidence that having more than one extended role would help to implement the use of these skills in practice: 'if all nurses had the oral health and fluoride certificates then more time could be given to the nurses to give sessions to support patients that are in need of oral health advice and applying the varnish could also reduce the risk of caries' (participant 29, salaried primary dental care).

One nurse felt that the course didn't have a positive impact on their career and had carried out only six fluoride varnish treatments in the 12 months, reportedly due to lack of clarity about issues relating to job descriptions and insurance.

The above views were endorsed in comments given at the end of the survey related to use of skills and remuneration: 'my main problem at the moment is [that] I am not being used as much as I would like let alone being paid more for it or having a new job role, which I feel is unfair' (participant 21, salaried primary dental care service).

It was suggested that there should be commitment from their practice to enable them to use the skills they have obtained: 'I would like that when the principal sends the nurses for any course [to] commit themselves to [allow] the nurse to use the skills and not just because [it] looks good and is something that has to be done, and give us the time and respect to do it' (participant 33, general dental practice).

\section{DISCUSSION}

Health systems across Europe are exploring greater use of skill-mix or staff-mix within healthcare ${ }^{6}$ and UK dentistry is taking this further with the advent of extended roles for dental nurses. ${ }^{3,4}$ The first four cohorts of dental nurses who successfully completed the training programme provided an estimated 2,500 fluoride applications.
The majority (56\%) of respondents were employed in salaried primary dental care services, which have traditionally been responsible for community programmes. These nurses reported the highest activity rates, followed by those in general dental practice, with hospital dental nurses reporting the least activity. Half of treatments were carried out as part of community programmes, where there is the potential for high volume activity and $41 \%$ in the dental surgery, each by a mix of salaried and practice-based nurses. If all respondents treated as many patients per month as the most productive nurse, some 38,590 fluoride applications could have been provided. Given that only six respondents were responsible for $71 \%$ of the fluoride application treatments there is clearly potential for greater utilisation of extended role dental nurses, particularly if a nurse receives regular referrals and has additional training. Such case studies need to be actively shared with the profession.

The evidence-based document Delivering Better Oral Health, ${ }^{2}$ advocates both a population and targeted high-risk approach to providing fluoride varnishing. Furthermore there is increasing emphasis on delivering fluoride varnish in community settings. ${ }^{1,7,8}$ Given the low complexity of the task trained dental nurses, as the largest workforce group in dentistry, ${ }^{9}$ are ideally placed to assist.

All but one of the dental nurses considered that the course had contributed to their professional career; this training is an example of 'role enhancement', ${ }^{9}$ whereby dental nurses 'step up' to take on a clinical role, albeit a 'delegated role'. They generally reported a high level of confidence about providing this treatment, particularly under supervision. This suggests that this course is successful in imparting the skills required for fluoride application by dental nurses.

For both types of nurses there were two types of skill-mix development: 'role enhancement', whereby dental nurses developed skills to work in the clinical environment and/or community settings, and 'role substitution' in taking over tasks from dentists, hygienists or therapists. ${ }^{6,9}$ Whereas dentists may be used to delegating to hygienists and perhaps therapists, this study suggests that there is significant organisational change required to delegate clinical tasks to a dental nurse. All of this activity involved 'role delegation' by a dental practitioner or consultant in dental public health in clinical and community settings respectively. ${ }^{9}$

Most nurses reported there were relevant resources available with the vast majority $(90 \%, \mathrm{n}=32)$ having fluoride varnish available to them; however, fewer nurses had surgery time allocated for this treatment, referrals from dentists or involvement in community programmes. Other barriers included having no dental public health consultant locally to take responsibility for a community programme in line with GDC guidance ${ }^{3}$ and problems with professional indemnity or consent. The findings suggest that clarity on issues of indemnity may also be needed as it appears that dental nurses may only be covered by the dentist's indemnity when carrying out work under the direct supervision of a dentist; cover for registered dental nurses fluoride application undertaken in line with the GDC's scope of practice document is an extra policy as part of their employer's membership. ${ }^{10,11}$ Clearly any nurse who is carrying out this extended role needs to be aware of the legal issues that may arise from their practice and ensure that appropriate arrangements are in place. A component on indemnity and legal issues should be integrated into the course content, as should teaching on how to take informed verbal consent. As most nurses attended the course due to personal interest it would seem that this interest could be used as a driver for the utilisation of their skills. This may be achieved by the inclusion of a component on how to run and implement fluoride application within their workplace and/or community projects. Thus, barriers to the use of extended role dental nurses (both systems barriers and professional barriers) need to be overcome, in order to support what is in effect both a service and a professional change.

Financial reward is linked to increasing professional status. ${ }^{12}$ Issues of appropriate remuneration were also raised by the nurses, which is something that must be incorporated into human resource management of extended duty nurses where there is role enhancement, otherwise there is the potential for disillusionment. ${ }^{9}$ If we are looking for the multi-professional dental team to provide efficient, effective and 
cost-effective oral health treatment then we must ensure skills acquired are being used efficiently and effectively and remunerated appropriately.

Limitations of this study include the low numbers included in this analysis. The response rate from nurses working in community dental practice was proportionally lower compared to the number attending the course. As a result of this bias, and considering that we know from the nurses who did respond that those in community carried out more fluoride application treatments, we may be underestimating the number of patients treated following this course. Further research in this field is recommended including the use, effectiveness and cost-effectiveness of developing one or more extended roles.

Following this research, we recommend that all nurses receiving fluoride varnish training are encouraged to develop an action plan with their employer to utilise their skills. Furthermore at system level it is important that proposed health services changes ${ }^{13,14}$ actively facilitate the use of extended role dental nurses in the delivery of preventive care as part of a systematic approach to health workforce management and improved public health. ${ }^{15}$

\section{CONCLUSION}

The findings highlight the potential for using extended roles to deliver evidencebased prevention and variation in their use; however, there is some evidence that organisational and professional barriers exist.

1. Marinho V C, Higgins J P, Sheiham A, Logan S Combinations of topical fluoride (toothpastes, mouthrinses, gels, varnishes) versus single topical fluoride for preventing dental caries in children and adolescents. Cochrane Database Syst Rev 2004: 1: CD002781.

2. Department of Health, British Association for the Study of Community Dentistry. Delivering Better Oral Health: an evidence-based toolkit for prevention. London: Department of Health and British Association for the Study of Community Dentistry, 2009.

3. General Dental Council. Scope of practice. London: General Dental Council, 2009

4. NHS Primary Care Commissioning. The use of fluoride varnish by dental nurses to control caries. London, 2009.

5. Dillman D A, Smyth J D, Christian L M. Internet mail and mixed-mode surveys: the tailored design method. 3rd ed. New York: John Wiley \& Sons, 2008.

6. McKee M, Dubois C A, Sibbald B. Changing professional boundaries. In Figueras J, McKee M, Mossialos E, Saltman R B (eds). European observatory on health systems and policies series: human resources for health in Europe. pp 63-78. Maidenhead: Open University Press, 2006.

7. Davies G M, Bridgman C, Hough D, Davies R M. The application of fluoride varnish in the prevention and control of dental caries. Dent Update 2009; 36: 410-412.

8. Beltrán-Aguilar E D, Goldstein J W, Lockwood S A. Fluoride varnishes. A review of their clinical use, cariostatic mechanism, efficacy and safety. J Am Dent Assoc 2000; 131: 589-596.

9. Dubois C A, Singh D. From staff-mix to skill-mix and beyond: towards a systematic approach to health workforce management. Hum Resour Health 2009; 7: 87.

10. Dental Protection UK. UK dental subscription rates. Dental Protection Ltd, 2011. Online article available at $h t t p: / / w w w . d e n t a l p r o t e c t i o n . o r g / a d x /$ aspx/adxGetMedia.aspx?DoclD=1167 (last accessed April 2012)

11. Dental Defence Union. DDU advises dentists and dental nurses on indemnity. Media release. London: DDU, 2008.

12. Macdonald K. The sociology of professions. London: Sage, 1995.

13. Steele J. NHS dental services in England: an independent review led by Professor Jimmy Steele. London: Department of Health, 2009.

14. Dental Programme Board. A review of skillmix in dentistry. London: Medical Education England, 2012.

15. NHS Future Forum. The NHS's role in the Public's Health. London: Department of Health, 2012. 